\title{
Importance of Nurses \& Midwives in the Upcoming Era [International Year of the Nurse and the Midwife (2020) Guest Comment]
}

Nurses and midwives play a central role in all health systems. They support people in every aspect of their health and wellbeing - from health promotion to chronic disease management and specialist services. ${ }^{1}$ Health 2020, the European policy framework for health and well-being was adopted by the 53 Member States of the Region at the sixty-second session of the WHO Regional Committee for Europe in September 2012. Health 2020 aims to support action across government and society to "significantly improve the health and well-being of populations, reduce health inequalities, strengthen public health and ensure people-centred health systems that are universal, equitable, sustainable and of high quality." ${ }^{2}$ Health 2020 also highlights nurses and midwives as having key personals and supposed to play important roles in society's efforts to tackle the public health challenges of our time, ensure the continuity of care and address peoples' rights and changing health needs. ${ }^{2}$

Nurses and midwives together form the largest health professional group in all countries ${ }^{2}$ and accounts nearly $50 \%$ of the global health workforce. There is a global shortage of health workers, in particular nurses and midwives, who represent more than $50 \%$ of the current shortage in health workers. The largest needs-based shortages of nurses and midwives are in South East Asia and Africa. For all countries to reach Sustainable Development Goal on health and wellbeing, WHO estimates that the world will need an additional 9 million nurses and midwives by the year 2030.

The Executive Board at its $144^{\text {th }}$ session in January 2019, considered the subject of human resources for health. The Board drew attention to the vital role and contributions of nurses and midwives in achieving universal health coverage. Noting that 2020 was the 2ooth anniversary of the birth of one of the founders of modern nursing, Florence Nightingale, the Board recommended to the Health Assembly to designate
2020 as the Year of the Nurse and the Midwife. ${ }^{3}$ As stated by Dr. Tedros Adhanom Ghebreyesus, director general of the World Health Organization (WHO) these two health professions are invaluable to the health of people everywhere. He further emphasis that "Without nurses and midwives, we will not achieve the sustainable development goals or universal health coverage." ${ }^{4}$

In developing countries like India both nurses and midwives play a vital role in promoting quality health services especially maternal and newborn health services, and can significantly help in reduction of maternal and new-born mortality and morbidity. The Government of India under the banner of Ministry of Health and Family Welfare formulated certain guidelines on midwives services and also recommends courses for midwifery training and certification so that the shortage of personals in this sector can be reduced. Much emphasis should be given in training and certifying number of personals especially women in this sector that can help in achieving good personal care and treatment within the communities and can play a key role in public health and controlling diseases and infections.

\section{REFERENCES}

1. Crisp N, Brownie S, Refsum C. Nursing and Midwifery: The key to the rapid and cost-effective expansion of high-quality universal health coverage. Doha, Qatar: World Innovation Summit for Health, 2018

2. Nurses and Midwives: A Vital Resource for Health European compendium of good practices in nursing and midwifery towards Health 2020 goals.

3. https://apps. who.int/gb/ebwha/pdf files/WHA72/ A 72 54Revi-en.pdf [Last Accessed on $12^{\text {th }}$ December, 2019]

4. https://www.nursingtimes.net/news/policies-andguidance/who-confirms-2020-as-international-yearof-nurse-and-midwife-24-05-2019 [Last Accessed on $12^{\text {th }}$ December, 2019] 
5. National Health Mission. Ministry of Health and Family Welfare, Government of India. Guidelines On Midwifery Services In India 2018. [Online PDF]. Available
https://nhm.gov.in/New Updates 2018/NHM Comp onents/RMNCHA/MH/Guidelines/Guidelines on $\mathrm{Mi}$ dwifery Services in India.pdf [Last Accessed on $12^{\text {th }}$ December, 2019]

\section{Cite this article as:}

Vaid N. Mechanism of Anti-Cancer Therapy Alopecia: An Achievement. Int Healthc Res J. 2020;3(10):314-315. https://doi.org/10.26440/IHRJ/0310.01171 